\title{
PENGARUH KUALITAS PELAYANAN TERHADAP KEPUASAN KONSUMEN PADA JALUR NUGRAHA EKAKURIR (JNE) KABUPATEN BIMA
}

\author{
Ahmad \\ Sekolah Tinggi Ilmu Ekonomi Bima \\ ahmadsamili58@gmail.com \\ Kartin Aprianti \\ Sekolah Tinggi Ilmu Ekonomi Bima \\ kartinaprianti93@gmail.com
}

\begin{abstract}
This study aims to determine whether there is an effect of service quality on consumers on the Nugraha Ekakurir (JNE) route, Bima Regency. The population used is all consumers who make transactions on the Nugraha Ekakurir (JNE) route in Bima Regency. The researcher limited the research to JNE which is located in Padolo, Bima Regency. The choice of this location is because Padolo, Bima Regency is located in the middle of the city so that it is easily accessible by the community. Therefore, to determine the number of samples in the unknown population, the unknown population formula is used so that 96 respondents are obtained. The sampling technique used is accidental sampling, namely JNE consumers who accidentally meet the researcher can be used as a sample tailored to the needs of the researcher. The results of this study indicate that Service Quality has a positive and significant effect on Customer Satisfaction at JNE, Bima Regency. The magnitude of the influence of service quality on customer satisfaction at JNE, Bima Regency is $29.4 \%$
\end{abstract}

Keywords: Service Quality, Customer Satisfaction, JNE

\begin{abstract}
ABSTRAK
Penelitian ini bertujuan untuk mengetahui ada tidaknya pengaruh kualitas pelayanan terhadap konsumen pada Jalur Nugraha Ekakurir (JNE) Kabupaten Bima. Populasi yang di gunakan yaitu seluruh konsumen yang melakukan transaksi di jalur nugraha ekakurir (JNE) Kabupaten Bima. Peneliti membatas penelitian hanya di JNE yang terletak di Padolo Kabupaten Bima. Pemilihan lokasi ini dikarenakan Padolo Kabupaten Bima terletak di tengah kota sehingga mudah dijangkau oleh masyarakat. Oleh karena itu untuk menentukan jumlah sampel dalam populasi yang tidak di ketahui maka di gunakan rumus unknown population sehingga diperoleh 96 reponden. Teknik sampling yang digunakan yaitu accidental sampling yaitu konsumen JNE yang secara kebetulan bertemu dengan peneliti dapat digunakan sebagai sampel disesuaikan dengan kebutuhan peneliti. Hasil penelitian ini menunjukkan bahwa kualitas pelayan berpengaruh positif dan signifikan terhadap kepuasan konsumen pada JNE Kabupaten Bima. Besarnya pengaruh kualitas pelayanan terhadap kepuasan konsumen pada JNE kabupaten bima sebesar 29,4\%
\end{abstract}

Kata Kunci : Kualitas Pelayanan, Kepuasan Konsumen, JNE 


\section{PENDAHULUAN}

Di era globalisasi saat ini perusahaan dituntut untuk meningkatkan pelayanan secara profesional sesuai dengan bidangnya masing-masing. Perubahan teknologi dan arus informasi yang semakin maju telah mendorong perusahaan untuk menghasilkan produk atau layanan yang dapat memenuhi kebutuhan dan keinginan konsumen. Hal ini dapat dilihat dari ketatnya persaingan yang terjadi di antara sekian banyak perusahaan. Semakin banyak perusahaan yang berkembang, maka persaingan pun akan semakin menjadi lebih ketat. Persaingan perusahaan pada masa kini bukan lagi berorientasi pada cara meningkatkan volume penjualan tetapi lebih berorientasi bagaimana memuaskan kebutuhan pelanggan. Dalam kondisi persaingan yang ketat seperti ini, hal utama yang harus diperhatikan dan diprioritaskan adalah memuaskan konsumen, supaya konsumen dapat bertahan dan perusahaan dapat bersaing dengan pesaing yang lain serta dapat menguasai pangsa pasar. Salah satu perusahaan yang bergerak dalam bidang jasa pengiriman adalah PT. JNE Express Across Nations. PT JNE merupakan salah satu perusahaan penyedia jasa logistik terkenal dan terluas di Indonesia dan berpusat di Jakarta dan mempunyai cabang-cabang di beberapa kota di Indonesia termasuk di kota Bima dan kabupaten Bima. Salah satu cabang yang berada di wilayah Kabupaten Bima beralamat di Desa Padolo Kecamatan Palibelo Jalan Lintas Sumbawa Bima, merupakan suatu anak cabang yang ada diwilayah tersebut guna memudahkan konsumen yang berada di wilayah kabupaten untuk mendapatkan barang pesanan mereka. Mempunyai pelanggan yang banyak dan cukup diperhitungkan oleh para pesaingnya yang juga bergerak dibidang yang sama. PT JNE sebagai penyedia jasa pengiriman barang dimana berfungsi sebagai penghubung antar pihak-pihak yang mempercayakan pengiriman barang melalui perusahaan tersebut, dituntut untuk melakukan pelayanan yang memuaskan bagi para pelanggannya baik secara individu maupun pelanggan bisnis. PT JNE mempunyai service pengiriman SS (super speed), YES (Yakin Esok Sampai), REGULER, OKE (Ongkos Kirim Ekonomis). Melakukan pelayanan pengiriman dalam bentuk paket, dokumen, kendaraan, dan lain - lain. Persaingan perusahaan di bidang jasa pengiriman pada masa kini bukan lagi berorientasi pada cara meningkatkan volume penjualan tetapi lebih berorientasi bagaimana memuaskan 
konsumen. Dalam keadaan yang seperti ini, salah satu cara untuk memenangkan persaingan adalah dengan meningkatkan kualitas pelayanan dengan sebaik mungkin sehingga konsumen akan merasa puas dan perusahaan akan tetap bertahan. penelitian Maulana (2016) menyatakan bahwa ualitas pelayanan adalah keunggulan yang diharapkan dan pengendalian atas tingkat keunggulan tersebut untuk memenuhi keinginan pelanggan. Hal ini berarti Jika mampu memenuhi keinginan pelanggan maka pelanggan akan merasa puas terhadap pelayanan yang diberikan. Kepuasan konsumen adalah perasaan senang atau kecewa seseorang yang muncul setelah membandingkan kinerja (hasil) produk atau jasa yang dipikirkan terhadap kinerja yang diharapkan (Fandi, 2011). Berdasarkan observasi awal yang telah dilakukan ternyata masih adanya ketidakpuasan para konsumen akan kinerjadari kurir PT JNE yang berlokasi di Desa Padolo, Kecamatan Palibelo, Kabupaten Bima. Salah satu bentuk ketidakpuasan konsumen pada pelayanan yang dberikan oleh pegawai maupun kurir PT JNE tersebut seperti ruang tunggu yang masih kurang nyaman bagi konsumen yang datang untuk melakukan pengiriman maupun pengambilan paket, kurir yang kurang ramah dalam pelayanan pengantaran paket, selain itu konsumen juga mengeluhkan terkait pengambilan barang dikantor JNE barus menunggu lama karena harus dicari terlebih dahulu oleh pegawai expedisi tersebut. Hal ini mengakibatkan konsumen harus menunggu lebih lama dari waktu yang ditentukan dan bahkan harus mengambil sendiri ke kantor JNE tersebut. Ketidakpuasan lain yang dirasakan konsumen juga seperti barang yang datang dalam keadaan rusak, barang yang diterima konsumen sudah tidak dalam bentuk kemasan yang baik (penyok, robek, terlihat isinya dll). Hal tersebut yang menyebab konsumen kurang puas dengan pelayanan expedisi JNE di Kabupaten Bima. Pelanggan akan merasa puas apabila keinginan mereka dapat terpenuhi sesuai dengan keinginan yang telah diharapkan. Berdasarkan uraian dari latar belakang di atas maka peneliti tertarik untuk melakukan penelitian mengenai "Pengaruh Kualitas Pelayanan Terhadap Kepuasan Konsumen Pada Jalur Nugraha Ekakurir (JNE) Kabupaten Bima 


\section{TELAAH LITERATUR}

\section{Kualitas Pelayanan}

(Prihandoyo, 2019) menyatakan bahwa "kualitas pelayanan adalah tingkat keunggulan yang diharapkan dan pengendalian atas tingkat keunggulan tersebut untuk memenuhi keinginan pelanggan". Menurut Kotler dalam penelitian (Tiza \& Susanti, 2018) mengungkapkan bahwa kualitas pelayanan adalah suatu cara kerja perusahaan yang berusaha mengadakan perbaikan mutu secara terus menerus terhadap proses, produk dan servis yang dihasilkan perusahaan. Khorista (2015) juga menjelaskan bahwa kualitas pelayanan adalah suatu keunggulan perusahaan untuk meningkatkan perusahaan agar konsumen tertarik. Indikator Kualitas Pelayanan dalam penelitian (Prihandoyo, 2019) yangmenjadi acuan dalam penelitian ini

\section{Kepuasan Konsumen}

Menurut (Kotler, 2012) Kepuasan konsumen adalah perasaan senang atau kecewa seseorang yang muncul setelah membandingkan kinerja (hasil) produk atau jasa yang dipikirkan terhadap kinerja yang diharapkan. menurut (Tjiptono, 2011), kepuasan konsumen adalah keadaan yang di perlihatkan oleh konsumen ketika mereka telah menggunakan jasa kemudian menyadari yaitu:

1. Bukti Fisik (Tangibles) yaitu berupa penampilan fasilitas fisik, peralatan, pegawai,dan material yang dipasang

2. Keandalan (Reliability) yaitu kemampuan untuk memberikan jasa yang dijanjikan dengan handal dan akurat

3. Daya Tanggap (Responsiveness) yaitu kesadaran dan keinginan untuk membantu pelanggan dan memberikan jasa dengan cepat

4. Jaminan (Assurance) yaitu pengetahuan, sopan santun, dan kemampuan karyawan untuk menimbulkan keyakinan dan kepercayaan.

5. Empati (Empathy) yaitu kepedulian, dan perhatian secara pribadi yang diberikan kepada pelanggan.

bahwa kebutuhan dan keinginannya telah sesuai dengan yang di harapkan serta terpenuhi secara baik. Hal yang serupa juga dikemukakan oleh (Tiza \& Susanti, 2018) bahwa kepuasan konsumen adalah perasaan senang atau kecewa konsumen saat menggunakan jasa ini dan kebutuhannya telah sesuai dengan harapan yang di inginkan oleh konsumen. Indikator kepuasan 
konsumen, penelitian (Tiza \& Susanti, 2018) yang menjadi acuan dalam penelitian ini adalah:

1. kepuasan secara keseluruhan (overall customer satisfation) diartikan sebagai perasaan puas, rasa senang dan kelegaan seseorang dikarenakan mengkonsumsi suatu produk atau jasa telah mendapatkan pelayanan suatu jasa dengan baik

2. minat pembelian ulang adalah kenginan dan tindakan konsumen untuk membeli ulang suatu produk, karena adanya kepuasan yang diterima sesuai yang dinginkan dari suatu produk.

3. Kesediaan untuk merekomendasikan adalah suatu bentuk komunikasi sekaligus promosi tidak langsung

\section{METODOLOGI PENELITIAN}

Jenis penelitian yang akan digunakan dalam penelitian ini adalah asosiatif. Menurut (Sugiyono, 2012) penelitian asosiatif bertujuan untuk mengetahui pegaruh antara variabel yang diteliti. Dalam penelitian ini bertujuan untuk mengetahui pengaruh kualitas pelayanan terhadap kepuasan konsumen. Populasi yang di gunakan yaitu seluruh konsumen yang melakukan transaksi di jalur nugraha ekakurir (JNE) kabupaten bima. Mengingat agen JNE di Kabupaten Bima yang jumlahnya sangat banyak, peneliti yang di lakukan oleh para konsumen yang sudah pernah membeli produk atau jasa yang kemudian mencerikan sebagai pengalamannya yang berkaitan dengan produk atau jasa tersebut pada orang lain.

\section{Hipotesis Penelitian}

Ho; $\beta=0$, tidak terdapat pengaruh positif dan signifikan kualitas pelayanan tidak berpengaruh secara signifikan terhadap kepuasan konsumen pada PT. Jalur Nugraha Ekakurir (JNE) Padolo Kabupaten Bima

$\mathrm{H}_{\mathrm{a}} ; \beta \neq 0$, terdapat pengaruh positif dan signifikan kualitas pelayanan berpengaruh signifikan terhadap kepuasan konsumen pada PT. Jalur Nugraha Ekakurir (JNE) Padolo Kabupaten Bima

membatas penelitian hanya di JNE yang terletak di Padolo Kabupaten Bima. Pemilihan lokasi ini dikarenakan Padolo Kabupaten Bima terletak di tengah kota sehingga mudah dijangkau oleh masyarakat, untuk menentukan jumlah sampel dalam populasi yang tidak di ketahui maka di gunakan rumus unknown population sehingga diperoleh 96 reponden. Teknik sampling yang digunakan yaitu accidental sampling yaitu konsumen JNE yang secara kebetulan bertemu dengan peneliti dapat 
digunakan sebagai sampel disesuaikan dengan kebutuhan peneliti. Teknik pengumpulan data adalah hal yang paling vital dalam suatu penelitian, oleh karena itu ada beberapa teknik yang digunakan dalam pengumpulan data. Cara peneliti dalam memperoleh data yang diperlukan dalam penelitian ini antara lain:

1. Observasi yaitu penelitian yang digunakan secara langsung oleh peneliti terhadap subjek penelitian yang diteliti untuk mendapatkan gambaran mengenai perusahaan sehingga data yang diperoleh dapat dipertanggungjawabkan

\section{HASIL DAN PEMBAHASAN}

\section{Uji Validitas dan Reliabilitas}

Hasil uji validitas dalam penelitian ini diperoleh nilai Corrected Item-Total Correlation $>0,3$ sehingga dapat ditarik kebenarannya.

2. Angket (Kuesioner) adalah teknik pengumpulan data yang dilakukan dengan cara memberi seperangkat pertanyaan atau pernyataan tertulis kepada responden untuk dijawabnya.

3. Studi Pustaka merupakan pengumpulan teori yang berhubungan dengan pembahasan penulisan ini dengan mempelajari dan mengutip teori dari berbagai buku dan literatur yang terdapat di perpustakaan maupun hasil penelitian terdahulu yang berkaitan dengan penelitian ini

kesimpulan bahwa item-item kuesioner dalam penelitian ini dinyatakan valid

Tabel 1. Uji Reliabilitas

\begin{tabular}{|l|c|c|c|}
\hline Variabel & $\begin{array}{c}\text { Cronbach's } \\
\text { Alpha }\end{array}$ & $\begin{array}{c}\text { Standar } \\
\text { Reliabel }\end{array}$ & Keterangan \\
\hline $\begin{array}{l}\text { Kualitas } \\
\text { Pelayanan }\end{array}$ & 0,864 & $>0,6$ & Reliabel \\
\hline $\begin{array}{l}\text { Kepuasan } \\
\text { Konsumen }\end{array}$ & 0,827 & $>0,6$ & Reliabel \\
\hline
\end{tabular}

Berdasarkan Tabel 1 diatas, diperoleh nilai Cronbach's Alpha sebesar 0,864 untuk variabel $\mathrm{X}$ dan 0,827 untuk variabel Y dan nilai tersebut lebih besar dari 0,6 sehingga dapat disimpulkan bahwa item pertanyaan dinyatakan reliable atau konsisten 


\section{Regresi Linier Sederhana}

Tabel 2. Regresi Linier Sederhana

\begin{tabular}{|c|c|c|c|c|c|c|}
\hline & \multirow{2}{*}{ Model } & \multicolumn{2}{|c|}{$\begin{array}{l}\text { Unstandardized } \\
\text { Coefficients }\end{array}$} & \multirow{2}{*}{$\begin{array}{c}\text { Standardized } \\
\text { Coefficients } \\
\text { Beta }\end{array}$} & \multirow[b]{2}{*}{$\mathrm{t}$} & \multirow[b]{2}{*}{ Sig. } \\
\hline & & B & $\begin{array}{l}\text { Std. } \\
\text { Error }\end{array}$ & & & \\
\hline \multirow[t]{2}{*}{1} & (Constant) & 15.901 & 3.352 & & 4.743 & .000 \\
\hline & $\begin{array}{l}\text { KUALITAS } \\
\text { PELAYANAN }\end{array}$ & .338 & .054 & .542 & 6.254 & .000 \\
\hline & endent Vari & KEP & SAN & KONSUMEN & & \\
\hline
\end{tabular}

Berdasarkan Tabel 2. diatas, diperoleh persamaan regresi linier sederhana sebagai berikut: $Y=\mathbf{a}+\mathbf{b X}$ yang $\operatorname{mana} \mathrm{Y}=\mathbf{1 5 , 9 0 1}$ $+\mathbf{0 , 3 3 8 X}$.

Keterangan:

$\mathrm{a}=15,901$, artinya jika variabel kualitas pelayanan $(\mathrm{X})$ nilainya ada 0 maka nilai kepuasan konsumen (Y) nilainya positif Sebesar 15,901

$\mathrm{b}=0,338$, artinya jika variabel kualitas Pelayanan (X) meningkat sebesar 1 satuan maka akan meningkatkan variabel kepuasan kerja (Y) sebesar 0,338.

\section{Koefisien Korelasi}

Tabel 4. Koefisien Korelasi

\begin{tabular}{|l|c|r|r|r|}
\hline Model & $\mathrm{R}$ & $\mathrm{R}$ Square & Adjusted R Square & $\begin{array}{c}\text { Std. Error of the } \\
\text { Estimate }\end{array}$ \\
\hline 1 & $.542^{\mathrm{a}}$ & .294 & .286 & 3.883 \\
\hline
\end{tabular}

Berdasarkan tabel 4 diatas, diperoleh nilai pada $0,40-0,599$ yang artinya hubungan $\mathrm{R}=0,542$. Nilai $\mathrm{R}$ tersebut berdasarkan antara Kualitas Pelayanan terhadap tabel 1. Koefisien Korelasi maka berada Kepuasan Konsumen adalah sedang .

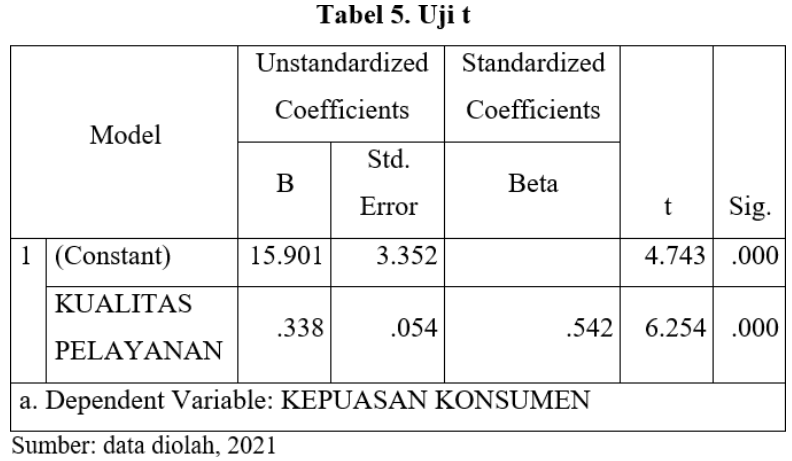

Berdasarkan Tabel 5 diatas, diperoleh nilai signifikansi $0,000<0,05$ dan nilai t hitung
6,254 > t table 1,989 maka Ha diterima, Ho ditolak artinya Kualitas Pelayan 
berpengaruh positif dan signifikan terhadap Kepuasan Konsumen. Hasil penelitian ini sejalan dengan hasil penelitian yang dilakukan oleh (Prihandoyo, 2019)yang juga membuktikan bahwa terdapat pengaruh positif dan signifikan pada kualitas pelayanan terhadap kepuasan SIMPULAN

Kualitas Pelayan berpengaruh positif dan signifikan terhadap Kepuasan Konsumen pada JNE Kabupaten Bima. Besarnya

\section{Saran}

1. Perusahaan JNE untuk terus meningkatkan kualitas pelayanan, sebaiknya kurir tersebut harus bisa meningkatkan kualitas pekerjaan mereka, sehingga dapat meningkatkan kualitas pekerjaan yang mereka lakukan yang dibutuhkan agar bisa menciptakan rasa puas konsumen terhadap pelayanan yang diberikan.

2. Karyawan pada perusahaan JNE untuk terus meningkatkan kepuasan konsumen dengan selalu memperhatikan konsumen setiap kali dalam melayani pengantaran dan pengiriman yang mereka lakukan kepada konsumen terhadap pelayanan yang diberikan agar bisa menciptakan kepuasan tersendiri bagi konsumen agar tetap menggunakan pelanggan JNE cabang Balikpapan. Hasil penelitian lain juga yang dilakukan oleh (Afrinda, Yulianto, \& Mawardi, 2015) juga diperoleh bahwa terdapat pengaruh positif dan signifikan antara kualitas pelayanan terhadap kepuasan pelanggan (Survey Pada Pelanggan Fedex Express Surabaya).

pengaruh kualitas pelayanan terhadap kepuasan konsumen pada JNE kabupaten bima sebesar $29,4 \%$.

pengiriman dan pengataran barang menggunakan espedisi JNE tersebut.

3. Bagi peneliti selanjutnya, diharapkan di masa yang akan datang dapat digunakan sebagai salah satu sumber data untuk penelitian selanjutnya dan dapat dilakukan penelitian lebih lanjut berdasarkan faktor lainnya, variabel yang berbeda, jumlah sampel yang lebih banyak, tempat berbeda, desain yang lebih tepat dan tetap berhubungan dengan Kualitas Pelayanan dan Kepuasan Konsumen 


\section{DAFTAR PUSTAKA}

Afrinda, K., Yulianto, E., \& Mawardi, M. K. (2015). Pengaruh Kualitas Pelayanan Terhadap kepuasan pelanggan (survey pada pelanggan Fedex Express Surabaya). Jurnal Administrasi Bisnis vol. 25 no.2, 17.

Kotler, P. (2012). Marketing management, (The Millenium Edition). New Jersey: Prentice-Hall.

Maulana, A. S. (2016). Pengaruh Kualitas Pelayanan Terhadap Kepuasan Pelanggan PT. Toi. Jurnal Ekonomi $7(2)$.

Prihandoyo, C. (2019). Pengaruh Kualitas Pelayanan Terhadap Kepuasan
Pelanggan JNE Cabang Balikpapan. Jurnal Geo Ekonomi, 116-129.

Sugiyono. (2012). Metode pendekatan penelitian Kuantitatif - kualitatif. Bandung: Alfabeta.

Suharsaputra, U. (2012). Metode penelitian: kuantitatif, kualitatif, dan tindakan. Bandung: Refika Aditama.

Tiza, M. F., \& Susanti, F. (2018). Pengaruh Pelayanan Terhadap Kepuasan Pelanggan Pada JNE Cabang Padang. OSF, Vol.5 No,2, 1-8.

Tjiptono, F. (2011). Manajemen jasa yogyakarta. yogyakarta: Penerbit Andi. 